Article

\title{
Vibration Reduction Strategy for Offshore Wind Turbines
}

\author{
Haoming Liu *(D), Suxiang Yang, Wei Tian, Min Zhao, Xiaoling Yuan and Bofeng Xu \\ College of Energy and Electrical Engineering, Hohai University, Nanjing 211100, China; \\ yangsuxiang@hhu.edu.cn (S.Y.); tian.wei@aliyun.com (W.T.); 15150645047@163.com (M.Z.); \\ yuanxiaoling97@163.com (X.Y.); bfxu1985@hhu.edu.cn (B.X.) \\ * Correspondence: liuhaom@hhu.edu.cn
}

Received: 23 July 2020; Accepted: 28 August 2020; Published: 2 September 2020

\begin{abstract}
The operational environment of offshore wind turbines is much more complex than that of onshore wind turbines. Facing the persistent wind and wave forces, offshore wind turbines are prone to vibration problems, which are not conducive to their long-term operation. Under this background, first, how the wave affects the vibration characteristics of offshore wind turbines is analyzed. Based on the existing wave and wave load models, we analytically show that there exist fluctuating components related to the hydrodynamic frequency in the aerodynamic load and aerodynamic torque of offshore wind turbines. Simulation results based on a GH Bladed platform further validates the analysis. Second, in order to reduce the joint impacts of the wave, wind shear and tower shadow on the wind turbine, a variable pitch control method is proposed. The integrated tower top vibration acceleration signal is superimposed on the collective pitch reference signal, then the triple frequency (3P) fluctuating component of the wind turbine output power and the azimuth angle of each blade are converted into the pitch angle adjustment signal of each blade, which is superimposed on the collective pitch signal for individual pitch control. The simulation results show that the proposed pitch control strategy can effectively smooth the fluctuation of blade root flap-wise load caused by wind and wave, and significantly reduce the fluctuation of aerodynamic torque and output power of offshore wind turbines.
\end{abstract}

Keywords: wind force; wave force; aerodynamic load; aerodynamic torque; pitch control; vibration reduction

\section{Introduction}

Offshore wind power is inevitably becoming an important clean energy source in coastal areas of China due to its advantages of high wind speed, low turbulence intensity and no occupation of land area [1]. However, compared with onshore wind turbines, offshore wind turbines face a more complex environment. Sustainable wind and wave forces on the structure of wind turbines are prone to vibration problems, which not only affect the normal operation characteristics of offshore wind turbines and reduce the output power quality, but also increase the fatigue load of the components of the wind turbines and shorten the life of the units. Therefore, when analyzing the vibration characteristics of offshore wind turbines, the effects of wind and wave on them should be fully considered.

The research on the influence of wind on the vibration characteristics of wind turbines shows that with the continuous expansion of wind turbine blades, wind shear and tower shadow cause a great imbalance of the wind speed distribution in the rotating plane of wind turbines, which causes the aerodynamic load of wind turbines to pulsate mainly at the 1P frequency [2], and the aerodynamic torque to pulsate mainly at the $3 \mathrm{P}$ frequency [3]. The term ' $\mathrm{P}$ ' refers to per revolution and indicates multiples of the rotational frequency of the turbine. In addition, due to wind shear and tower shadow, 
the periodic aerodynamic load acts on the tower, which makes the tower fore-aft moment fluctuate, and then the fore-aft vibrations of the tower occur.

There have been many achievements in the research on vibration reduction of onshore wind turbines and the pitch control methods, especially the individual pitch control methods, which have been proved to be common and effective methods for wind turbine vibration reduction. In general, such researches can be summarized into three groups. First, some literature concentrates on the tower vibration reduction by pitch control methods. Based on analyzing the causes of tower vibration, the optimization control strategy is proposed by increasing the tiny pitch angle in the pitch control system, which can increase the aerodynamic damping of the tower. The proposed strategy can effectively reduce the fore-aft vibration and torque of tower, and has little influence on the power [4]. Lio et al. [5] presented a method to estimate the tower fore-aft velocity using the measured data of blade load sensors and a control strategy of increasing tower damping based upon an individual pitch control architecture. Second, a number of pitch control strategies for structural load control in blades or rotor have been proposed. It was found that the individual pitch control method is very effective for smoothing the fluctuation of the blade root load of wind turbines in [6,7]. Coral-Enriquez et al. [8] provided two individual pitch control schemes to attenuate the main periodic load components of blade flap-wise and hub yaw/tilt-wise bending moments in wind turbines under varying-frequency conditions. Jones et al. [9] pointed out the limitations of conventional individual pitch control based on blade root load feedback, and then presented an additional cascaded feedback controller based upon a local blade inflow measurement on each blade to better reduce blade root flap-wise load. Ossmann et al. [10] designed an individual blade pitch control law using multivariable linear parameter-varying control techniques to reduce the structural loads both on the rotating and non-rotating parts of the turbine. Fitzgerald et al. [11] provided a novel individual pitch control strategy using a wavelet linear quadratic regulator control algorithm to reduce blade vibration. Civelek et al. [12] proposed a new fuzzy logic proportional control approach applied to individual pitch angles, which can mitigate the moment load on the blades and tower to a minimum possible value while keeping the output power of wind turbines at a constant value. He et al. [13] investigated the combined pitch and trailing edge flap control including an individual pitch control loop and a trailing edge flap control loop for load mitigation of wind turbines. Mohammadi et al. [14] proposed a new control method by using two supplementary controllers an internal model controller with an adaptive algorithm and a standard individual pitch controller to suppress the tower vibrations and to reduce the fatigue loads of the wind turbine, with the internal model controller reducing the tower vibrations and the standard individual pitch controller reducing the fatigue loads of the wind turbine. The last group of literature look into pitch control methods to restrain the fluctuation of aerodynamic torque and output power. Zhang et al. [15] used the individual pitch control method to reduce the 3P fluctuating component of wind turbine output power, which is validated in different wind speed scenarios. Dou et al. [16] proposed a variable pitch control strategy, which periodically adjusts each blade's pitch angle by measuring the azimuth signal and distributing the azimuth weight coefficient to reduce the 3P pulsation component of wind turbine torque. Imran et al. [17] designed multivariable disturbance observer based linear controllers which can be used with individual pitch control with the objective of reducing output power fluctuation, tower oscillation and drive-train torsion by using optimal control theory. Tian et al. [18] proposed a new individual pitch control strategy for three-bladed wind turbines to reduce the 1P fluctuation component in the aerodynamic loads and the multiples of the 3P fluctuation component in the aerodynamic torque caused by wind shear and tower shadow.

However, at present, the effect of waves on wind turbines is mainly focused on the dynamic response, fatigue load, ultimate load, etc., of the foundation of offshore wind turbines under wave force [19-22]. The research object of the above research is only the offshore wind turbine tower. Nowadays, few studies have analyzed the effect of waves on blade load and wind turbine aerodynamic torque in the mechanism. Hemmati et al. [23] studied vibration control of offshore wind turbines induced by multi-hazard excitations and established a model consisting of the entire offshore wind 
turbine foundation and tower controlled by tuned liquid column dampers considering nonlinear soil pile interaction, which is subjected to wave, wind, and seismic loading. Numerical analysis results demonstrate the effectiveness of the optimal tuned liquid column dampers in reducing the fore-aft vibration of the tower. Namik and Stol [24] applied individual blade pitch state space control and disturbance accommodating control that reject wind speed perturbations on a $5 \mathrm{MW}$ wind turbine mounted on the barge and tension leg floating platforms for performance comparison in the above rated wind speed region, and simulation results show that individual blade pitch state space control can significantly reduce tower load. Namik and Stol [25] also presented the development of a periodic state space controller that utilizes individual blade pitching to improve power output and reduce platform motions of floating wind turbines in the above rated wind speed region. Sarkar et al. [26] proposed a wavelet multi-resolution based individual pitch control strategy for spar-type floating offshore wind turbines and investigated the performance of the proposed strategy under joint wind-wave-current loads considering the interaction between wave and current. Simulation results show that the aerodynamic loads can be decreased with this control strategy, which in turn reduces vibration in tower fore-aft and platform pitching motion of the wind turbine. However, in these studies, the mechanism of how waves affect the load of wind turbines and aerodynamic torque is not systematically analyzed.

Therefore, on the basis of studying the wind model and the influence of wind on the vibration characteristics of wind turbines [4,5], this paper concentrates on the impact of waves on the vibration characteristics of them and proposes an improved individual pitch control. The novelty of this study can be summarized into two parts. On the one hand, the effects of waves on wind turbine towers, blade load and aerodynamic torque are investigated by theoretical analysis and simulation. On the other hand, an improved individual pitch control strategy is proposed to reduce the fluctuation of the aerodynamic load and torque of the wind turbine under wind and waves. Based on the vibration acceleration signal of the tower top, the collective pitch angle can be adjusted to reduce the fluctuating component related to the hydrodynamic frequency in the aerodynamic load and torque. Then, the pitch angle of each blade is adjusted based on the output power of the wind turbine and the azimuth angle of the blade to further reduce the fluctuation of the aerodynamic load and torque of the wind turbine caused mainly by wind shear and tower shadow.

The rest of this paper is organized as follows: The mathematical model of a wave is established and the calculation method of wave force is presented in Section 2. The influence of waves on load and aerodynamic torque of wind turbines is analyzed in Section 3. Section 4 proposes a pitch angle control strategy for reducing load and torque pulsation caused by wind and wave. Section 5 presents the simulation results and Section 6 draws the conclusions.

\section{Wave Model and Wave Force Calculation}

In this paper, the vibration characteristics of offshore wind turbines under the influence of wind and waves are mainly studied. As is shown in Figure 1, the influence factors of wind include wind shear, tower shadow and turbulent wind, and the influence factors of waves include wave height and wave period. Some studies focus on the vibration characteristics of wind turbine under the influence of wind, especially the impact of wind shear and tower shadow [2,3]. To suppress the wind turbine vibration caused by wind, several control strategies have been studied $[5,8,14,17]$. The influence of waves on the vibration characteristics of the wind turbine needs further study, and the control strategy to suppress the vibration of the wind turbine caused by wind and waves needs to be proposed. To this end, a wave model and wave force calculation are studied.

There are two main research directions in the theory of wave modeling. One is regular wave theory, which uses hydrodynamics to reveal the motion of material particles in liquid. The other is random wave theory, which shows the distribution characteristics of wave energy in sea waves by studying the randomness of sea surface fluctuations. The random wave theory is derived from the former one. 


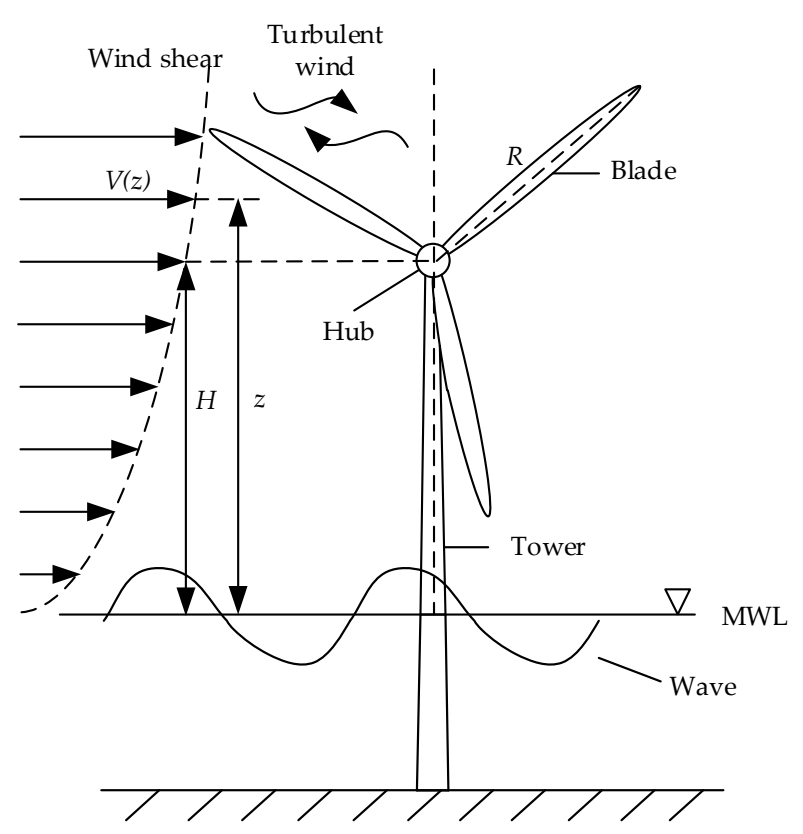

Figure 1. Operating environment of offshore wind turbine.

\subsection{Regular Wave Model}

In the regular wave model, the wave theory based on stream function takes into account the nonlinearity of waves and has many advantages. It can be widely used and extended to any order, which has good fitting conditions and can take into account the effect of ocean currents. It can simulate the near-breaking nonlinear wave in a shallow water well. The coordinate system is established based on a regular wave diagram, as is shown in Figure 2. The intersection point between the axis of the cylinder and the mean water level (MWL) is the coordinate origin, the direction of wave propagation is set to the $x$ axis, and the $z$ axis is vertical upward. Moreover, $h$ is the water depth, $D$ is the diameter of the tower, and $\eta$ is the height of the wave surface.

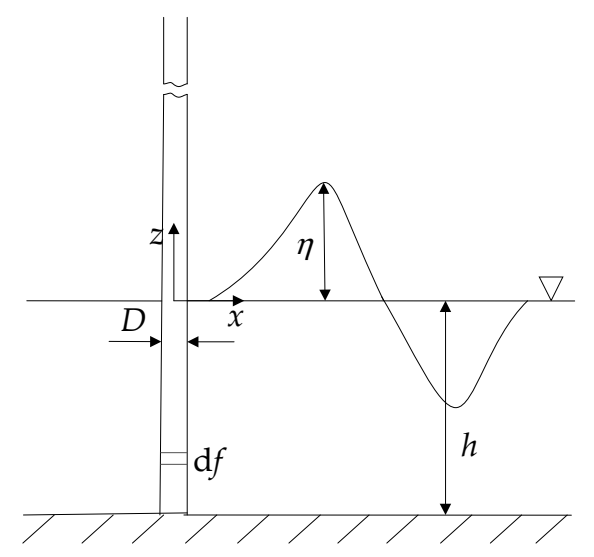

Figure 2. Simple schematic diagram of regular wave.

The wave model based on stream function can be expressed as [27]:

$$
\psi(x, z)=\frac{L}{T} z+\sum_{n=1}^{N} X(n) \sinh \left[\frac{2 \pi n}{L}(h+z)\right] \cos \left(\frac{2 \pi n x}{L}\right),
$$

where $X(n)$ is the coefficient of higher order perturbation term; $L$ is the wavelength; $T$ is the wave period. 
At the same time, the wave has periodicity both in time and space, which satisfies the boundary conditions: $\psi(x, z, t)=\psi(x+L, z, t), \psi(x, z, t)=\psi(x, z, t+T)$.

\subsection{Random Wave Model}

In fact, the wave situation is random, and the direction, size and period of the wave are irregular. The power spectrum of the wave is developed to reflect the energy distribution characteristics of random waves at different frequencies, and is an important means of describing random waves. At present, the commonly used wave spectrum includes Pierson Moskowitz (P-M) spectra, JONSWAP spectra $[23,28,29]$. They use semi-theoretical and semi-empirical formulas to describe the power spectral characteristics of random waves based on the observation of an actual wave. The one-sided DNV (Det Norske Veritas) version of the P-M spectra [28] is used in this paper.

$$
S_{\eta}=\frac{H_{s}^{2} T_{z}}{8 \pi^{2}}\left(T_{z} f\right)^{-5} \exp \left[-\frac{1}{\pi}\left(T_{z} f\right)^{-4}\right]
$$

where $f$ is the wave frequency in cycles per second; $H_{s}$ is the significant wave height, and $T_{z}$ is the zero up crossing period; $S_{\eta}$ is the single-sided P-M sea surface elevation spectrum.

The interval between two adjacent upward zero-crossing points recorded by the wave surface is usually defined as a period. From the P-M spectrum, the relationship between the peak spectrum period and zero up crossing period satisfies [30]

$$
T_{p}=\left(\frac{5 \pi}{4}\right)^{\frac{1}{4}} T_{z} \approx 1.41 T_{z}
$$

where $T_{p}$ is the peak spectral period.

\subsection{Calculation of Wave Force}

The diameter of the offshore wind turbine tower is relatively small compared with the wave length. According to Morison's theory, the wave force acting on the whole tower in direction $x, F_{x}$, can be expressed as [31]

$$
F_{x}=\int_{0}^{h+\eta} \frac{1}{2} C_{D} \rho_{s e a} D v_{x}\left|v_{x}\right| d z+\int_{0}^{h+\eta} C_{M} \rho_{s e a} \frac{\pi D^{2}}{4} \frac{\partial v_{x}}{\partial t} d z,
$$

where $v_{x}(t)$ is the velocity of the fluid particle in direction $x$ at time $t ; \partial v_{x} / \partial t$ is the acceleration of the fluid particle in direction $x ; \rho_{\text {sea }}$ is the density of seawater; $C_{D}$ is the hydraulic resistance coefficient, which is usually set as $0.7-1.2 ; C_{M}$ is the hydraulic inertia force coefficient, which is usually set as 1.7-2.0.

According to Equation (4), the horizontal wave moment is mainly related to variables $v_{x}(t)$ and $\eta$. Therefore, the wave period and wave height play a decisive role in the wave force acting on the offshore wind turbine structure.

\section{Effect of Wave on Load and Aerodynamic Torque of Wind Turbines}

In reality, sea waves are random and can be seen as the superposition of numerous regular waves with different amplitudes and frequencies. Therefore, to quantify the effects of random wave on the load and aerodynamic torque of wind turbines, we start with the evaluation of effects of regular waves. 


\subsection{Effect of Regular Waves on Tower}

The forced vibration of a structure will occur under the action of external forces. The forced vibration equation of the single degree of freedom system is expressed as follows:

$$
m \ddot{u}+c \dot{u}+k u=p(t)
$$

where $m$ is the mass of the system; $k$ is the bending stiffness; $c$ is the damping coefficient; $u$ is the displacement; $\dot{u}$ is the velocity; $\ddot{u}$ is the acceleration; $p(t)$ is the load varying with time.

When the load $p(t)$ is arbitrary periodic, it can be represented as a Fourier series as follows:

$$
p(t)=a_{0}+\sum_{n=1}^{\infty} a_{n} \cos \widetilde{\omega}_{n} t+\sum_{n=1}^{\infty} b_{n} \sin \widetilde{\omega}_{n} t
$$

where $a_{0}, a_{n}, b_{n}$ are the coefficients and $\widetilde{\omega}_{n}$ is the frequency of the $n$-th external load.

The steady-state response of the system can be expressed as follows [32]:

$$
u(t)=\frac{1}{k}\left(a_{0}+\sum_{n=1}^{\infty} \frac{1}{\left(1-\gamma_{n}^{2}\right)^{2}+\left(2 \xi \gamma_{n}\right)^{2}}\left\{\left[a_{n} 2 \xi \gamma_{n}+b_{n}\left(1-\gamma_{n}^{2}\right)\right] \sin \widetilde{\omega}_{n} t+\left[a_{n}\left(1-\gamma_{n}^{2}\right)-b_{n} 2 \xi \gamma_{n}\right] \cos \widetilde{\omega}_{n} t\right\}\right)
$$

where the frequency ratio is $\gamma_{n}=\frac{\widetilde{\omega}_{n}}{\omega}$; $\omega$ is the natural frequency of the system; $\xi$ is the ratio of the system damping to the critical damping.

In Equation (7), the vibration frequency of the system is the same as that of the external load, but there is a certain phase difference [32]. Therefore, when the waves periodically act on the tower, the fluctuating component of the hydrodynamic frequency in the load on the tower at the MWL will increase.

The part of the tower above the elevation of the wave surface is not directly affected by the wave, but it also faces the impact because the low frequency vibration caused by the wave will run through the whole tower system due to the small damping matrix term of the steel tube tower structure. The relationship between the bending moment at the bottom of the tower $M(t)$ and the horizontal displacement at the top of the tower $u_{\text {top }}(t)$ satisfies

$$
M(t)=K u_{t o p}(t) H
$$

where $K$ is the bending stiffness of the tower, the bending stiffness is the resistance of a member against bending deformation; and $H$ is the height of the tower.

Therefore, the top displacement and the bottom moment of the tower have the same waveform, that is, the vibration caused by wave will be transmitted from the bottom of the tower to the top of the tower. During this process, the vibration energy will be weakened because of the damping effect, but the vibration frequency will remain unchanged.

\subsection{Effect of Regular Waves on Blade Load and Aerodynamic Torque}

The relative wind speed on the wind turbine blade is the superposition of the wind speed and the blade's own motion speed. That is, when the tower top moves forward and backward, the relative wind speed of the blade will increase or decrease accordingly. The wind speed under the influence of tower motion can be expressed as

$$
V=V_{0}-\dot{u}_{t o p}
$$

where $V_{0}$ is the original wind speed; $\dot{u}_{\text {top }}$ is the tower top motion speed in the direction of wind speed. In the area where the wind blows, it is generally considered that the direction of wave propagation is consistent with the wind direction. Therefore, in this paper, we assume that the wind load and wave load acting on the wind turbine and the tower are in a consistent direction. 
The aerodynamic load of the wind turbine is directly related to the relative wind speed of the blade, and the former will change with the latter. When the load of the wind wheel acting on the tower changes, the tower deforms to varying degrees, which affects the relative wind speed. Therefore, there exists a dynamic coupling effect between the wind wheel and the tower during the whole vibration process of the wind turbine.

Without considering the blade-tower coupling effect, the root shear force of the rotating blade is the sum of the total inertial force of the blade, which can be expressed as [33]

$$
\left\{Q_{B}(t)\right\}=\sum_{i=1}^{n} m_{B i} \ddot{w}_{B i}(t),
$$

where $\left\{Q_{B}(t)\right\}$ is the blade root shear force; $m_{B i}$ is the mass of the blade element, and $\ddot{w}_{B i}(t)$ is the acceleration of the blade element.

When considering the blade-tower coupling effect, the effective shear force of a blade can be written as [34]

$$
\left\{\bar{Q}_{B}(t)\right\}=\sum_{i=1}^{n} m_{B i}\left(\ddot{w}_{B i}(t)+\ddot{u}_{t o p}(t)\right),
$$

where $\ddot{u}_{t o p}(t)$ is the acceleration of the tower top. Applying Equation (10) to Equation (11), we have

$$
\left\{\bar{Q}_{B}(t)\right\}=\sum_{i=1}^{n} m_{B i} \ddot{w}_{B i}(t)+\ddot{u}_{t o p} \sum_{i=1}^{n} m_{B i}=\left\{Q_{B}(t)\right\}+\ddot{u}_{t o p} M_{B}
$$

where $M_{B}$ is blade mass.

In Equation (12), the inertia effect of the tower top on the blade is considered, and the coupled equation can be decoupled by the method of additional mass in the process of solving. So, the shear force of a single blade is affected by its own mass distribution and acceleration, as well as the acceleration of the tower top. In other words, when considering the blade-tower coupling effect, the vibration of the tower top caused by the wave will add a shear force of the same frequency to the blade root in the same direction.

The relationship between the shear force of the blade root flap-wise direction $\bar{Q}_{B x}$ and the blade root flap-wise load $M_{B x}$ can be written as [35]

$$
M_{B x}=\int_{r_{0}}^{R} \bar{Q}_{B x} r d r=\int_{r_{0}}^{R}\left(Q_{B x}+\ddot{u}_{t o p} M_{B}\right) r d r,
$$

where $r_{0}$ is the hub radius; $R$ is the wind wheel radius; $r$ is the distance between the blade element and blade root.

The change of the relative wind speed of the blade will lead to the obvious change of the aerodynamic torque produced by the wind wheel.

$$
\begin{aligned}
T_{\text {aero }} & =\frac{1}{2} \rho_{\text {air }} \pi R^{3} C_{T}(V, \Omega, \beta) V^{2} \\
& =\frac{1}{2} \rho_{\text {air }} \pi R^{3} C_{T}(V, \Omega, \beta)\left(V_{0}-\dot{u}_{\text {top }}\right)^{2}
\end{aligned}
$$

where $\rho_{\text {air }}$ is air density; $C_{T}$ is the torque coefficient; $\Omega$ is wind wheel speed, and $\beta$ is pitch angle.

Linearize Equation (14) near any operating point and the following equation is obtained

$$
\hat{T}_{\text {aero }}=\left(T_{\text {aero }}\right)_{V}^{\prime} \hat{V}_{0}-\left(T_{\text {aero }}\right)_{V}^{\prime} \hat{\dot{u}}_{\text {top }}+\left(T_{\text {aero }}\right)_{\Omega}^{\prime} \hat{\Omega}+\left(T_{\text {aero }}\right)_{\beta}^{\prime} \hat{\beta},
$$

where $\hat{T}_{\text {aero }}, \hat{V}_{0}, \hat{\dot{u}}_{\text {top }}, \hat{\Omega}, \hat{\beta}$ are linear incremental functions of aerodynamic torque, original wind speed, the tower top motion speed in the direction of wind speed, rotor speed and pitch angle respectively; 
$\left(T_{\text {aero }}\right)_{V^{\prime}}^{\prime}\left(T_{\text {aero }}\right)_{\Omega^{\prime}}^{\prime}\left(T_{\text {aero }}\right)_{\beta}^{\prime}$ are the partial derivatives of aerodynamic torque at the linearization point of wind speed, wind turbine speed and pitch angle.

It can be seen from Equations (13) and (15) that the wave will result in the hydrodynamic frequency fluctuating component in both the blade root load and the aerodynamic torque, and the influence of the wave on aerodynamic torque is particularly noticeable.

The influence of a regular wave on load and aerodynamic torque of wind turbines is extended to that of a random wave on load and aerodynamic torque of wind turbines. A random wave can be seen as the superposition of numerous regular waves with different amplitudes and frequencies [36], therefore, the load and aerodynamic torque generated by the random wave acting on the wind turbines can be regarded as the superposition of the load and aerodynamic torque generated by several regular waves acting on the wind turbines. The vibration mechanism is consistent, but the hydrodynamic frequency is extended from a single value to a range.

\section{Pitch Angle Control Strategy for Reducing Load and Torque Pulsation}

The blades of wind turbines are affected by the beating waves transmitted from the tower and produce a low frequency vibration related to the hydrodynamic frequency. In practice, wind shear and tower shadow will make the wind speed unevenly distributed in the rotating plane of the wind wheel, resulting in $1 \mathrm{P}$ aerodynamic load pulsation and $3 \mathrm{P}$ aerodynamic torque pulsation. In this case, it is very important to adjust the blade pitch angle to improve the aerodynamic characteristics of the blade and the output power quality of the wind turbine from the source.

When the wave hits on the tower, the tower vibrates with a certain frequency, hence the relative wind speed changes correspondingly. Because the calculation of aerodynamic torque is directly related to the relative wind speed, the wave will have a certain impact on the aerodynamic torque, which is expressed in Equation (15). To reduce the fluctuating component of hydrodynamic frequency in aerodynamic torque, an additional torque $\Delta \hat{T}_{\text {aero }}=\left(T_{\text {aero }}\right)_{V}^{\prime} \hat{\dot{u}}_{\text {top }}$ can be added to the original aerodynamic torque, as shown in Equation (16), to suppress the aerodynamic torque disturbance caused by $\hat{\dot{u}}_{\text {top }}$.

$$
\hat{T}_{\text {aero }}+\Delta \hat{T}_{\text {aero }}=\left(T_{\text {aero }}\right)_{V}^{\prime} \hat{V}_{0}-\left(T_{\text {aero }}\right)_{V}^{\prime} \hat{\dot{u}}_{\text {top }}+\left(T_{\text {aero }}\right)_{\Omega}^{\prime} \hat{\Omega}+\left(T_{\text {aero }}\right)_{\beta}^{\prime} \hat{\beta}+\left(T_{\text {aero }}\right)_{V}^{\prime} \hat{\dot{u}}_{\text {top }}
$$

The additional aerodynamic torque component is realized by adding the pitch angle value on the basis of the reference value of the collective pitch angle $\beta_{\text {ref }}$. With the increase of pitch angle, the aerodynamic force captured by the blade decreases, and the aerodynamic torque decreases, and vice versa, showing a negative correlation. Therefore, the specific adjustment of pitch angle can be written as

$$
\beta_{r e f}^{\prime}=\beta_{r e f}-G^{\prime} \dot{u}_{t o p}
$$

where, $G^{\prime}$ is control gain value.

Combining Equations (15) and (17), the adjusted aerodynamic torque can be expressed as

$$
\hat{T}_{\text {aero }}+\Delta \hat{T}_{\text {aero }}=\left(T_{\text {aero }}\right)_{V}^{\prime} \hat{V}_{0}-\left(T_{\text {aero }}\right)_{V}^{\prime} \hat{\dot{u}}_{\text {top }}+\left(T_{\text {aero }}\right)_{\Omega}^{\prime} \hat{\Omega}+\left(T_{\text {aero }}\right)_{\beta}^{\prime} \hat{\beta}-\left(T_{\text {aero }}\right)_{\beta}^{\prime} G^{\prime} \hat{\dot{u}}_{\text {top }}
$$

so, $G^{\prime}=-\left(T_{\text {aero }}\right)_{V}^{\prime} /\left(T_{\text {aero }}\right)_{\beta}^{\prime}$. Because of the non-computability of the ratio, the value of $G^{\prime}$ can be determined through continuous experiments in the simulation.

Because it is easy to measure the acceleration of the tower, the tower speed can be obtained indirectly through the vibration acceleration of the tower in practical application [3]. So that

$$
\beta_{r e f}^{\prime}=\beta_{r e f}-G^{\prime} \int \ddot{u}_{t o p} .
$$

On the basis of collective pitch control, the pitch angle of each blade is adjusted independently. Because the aerodynamic torque is directly related to the output power, and the aerodynamic torque 
cannot be measured directly, in this paper, the low-pass filter is used to filter the 3P fluctuating component of the output power, which is converted into pitch angle adjustment signal $\Delta \beta$ by the PI controller. Then by combining the azimuth angle signal of each blade $\theta_{i}(i=1,2,3)$, the pitch angle adjustment signal of each blade $\Delta \beta_{i}$ is obtained [37], which is finally superimposed to the collective pitch angle $\beta_{r e f}^{\prime}$. By using the proposed pitch angle control strategy, the fluctuating component of hydrodynamic frequency in aerodynamic torque is reduced, as well as the 1P aerodynamic load fluctuation and 3P aerodynamic torque fluctuation of the wind turbine. The block diagram of variable pitch control is shown in Figure 3.

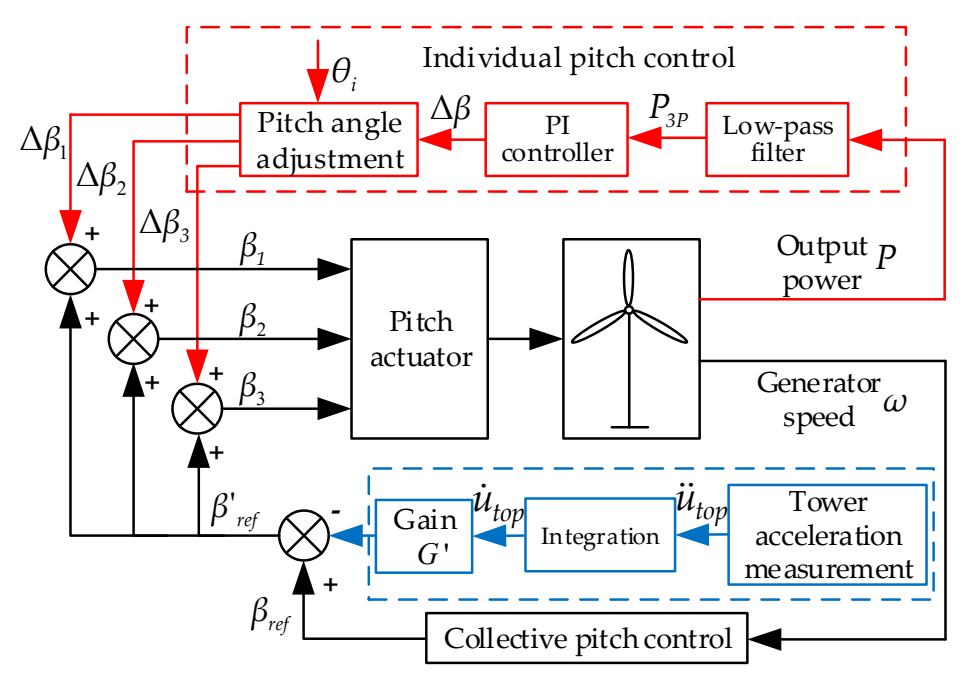

Figure 3. The proposed individual pitch control strategy.

The transfer function of the low-pass filter in Figure 3 can be written as

$$
G(s)=\frac{\lambda_{0} s^{2}+\lambda_{1} s+\lambda_{2}}{\mu_{0} s^{2}+\mu_{1} s+\mu_{2}}
$$

where $s$ is the Laplace operator, and $\lambda_{0}, \lambda_{1}, \lambda_{2}, \mu_{0}, \mu_{1}, \mu_{2}$ are transfer function parameters.

The proportional and integral coefficients of the PI controller can be expressed as $K_{p}$ and $K_{i}$, so $\Delta \beta$ can be expressed as

$$
\Delta \beta=K_{p} P_{3 P}(t)+K_{i} \int_{0}^{t} P_{3 P} d \tau(\tau)
$$

where $P_{3 P}(t)$ is the $3 P$ fluctuating component of the output power filtered by the low-pass filter.

Wind shear and tower shadow make the wind speed captured by each blade in the process of rotation closely related to the azimuth angle signal $\theta_{i}$ of the blade [38]. If the pitch angle of each blade changes periodically with the blade azimuth angle, the load fluctuation caused by the non-uniform wind speed will be effectively suppressed. The pitch angle of each blade can be written as

$$
\begin{aligned}
& \Delta \beta_{i}=\cos \theta_{i} \Delta \beta \\
& \beta_{i}=\beta_{r e f}^{\prime}+\Delta \beta_{i}
\end{aligned}
$$

\section{Simulation Study}

Simulation analysis was carried out on GH Bladed. In order to better verify the influence of sea wave on the vibration characteristics of wind turbines and the effectiveness of the proposed pitch angle control strategy, a $5 \mathrm{MW}$ single pile, three-blade, variable-speed, constant-frequency wind turbine was selected as the simulation unit. The $1 \mathrm{P}$ frequency of the wind turbine is $0.2268 \mathrm{~Hz}$, and the $3 \mathrm{P}$ frequency 
of the wind turbine is $0.6804 \mathrm{~Hz}$. Assume that the water depth is $25 \mathrm{~m}$, the hydrodynamic drag coefficient $C_{D}$ is 1 , and the hydrodynamic inertia force coefficient $C_{M}$ is 2 . When wind shear and tower shadow are considered, the wind shear coefficient is 0.11 , and the tower diameter correction factor is 1 . At this time, the wind turbine operates at the rated state, and the limits of pitch angle amplitude and change rate are set to $\left[0^{\circ}, 90^{\circ}\right]$ and $\left[-8^{\circ} / \mathrm{s}, 8^{\circ} / \mathrm{s}\right]$ [9], respectively. Because the 3P frequency of the wind turbine in this paper is $0.6804 \mathrm{~Hz}$, the frequency range of the low-pass filter is set to $0-1 \mathrm{~Hz}$, and the corresponding transfer function coefficients are $\lambda_{0}=0.067, \lambda_{1}=0.134, \lambda_{2}=0.067, \mu_{0}=1, \mu_{1}=-1.143$, $\mu_{2}=0.413$, respectively.

\subsection{Simulation and Verification of the Effect of Waves on Wind Turbine}

\subsubsection{Simulation and Verification of the Effect of Regular Waves on Wind Turbine}

In order to verify the existence of hydrodynamic frequency fluctuation components in wind turbine tower load, blade load and aerodynamic torque, the wind turbine load and aerodynamic torque with and without regular wave are simulated, as is shown in Figures 4-6. 'Without wave' refers to the operation of offshore wind turbines in a wind-only environment, while 'Regular wave 1 ' and 'Regular wave $2^{\prime}$ refer to the operation environment of offshore wind turbines containing both wind and regular wave. For simplification, wind shear and tower shadow are not considered here. In the simulation, the wind speed at the hub center is constant at $14 \mathrm{~m} / \mathrm{s}$, and the wind and wave are in a consistent direction. In 'Regular wave 1', the wave height is $2.0 \mathrm{~m}$, and the wave period is $6 \mathrm{~s}$. In 'Regular wave $2^{\prime}$, the wave height is $2.4 \mathrm{~m}$, and the wave period is $6 \mathrm{~s}$.

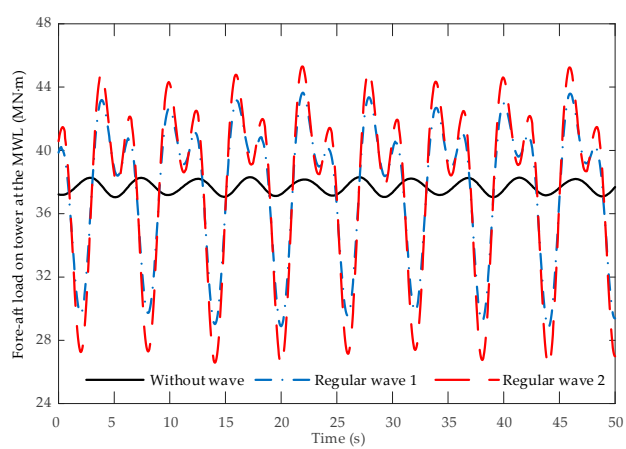

(a)

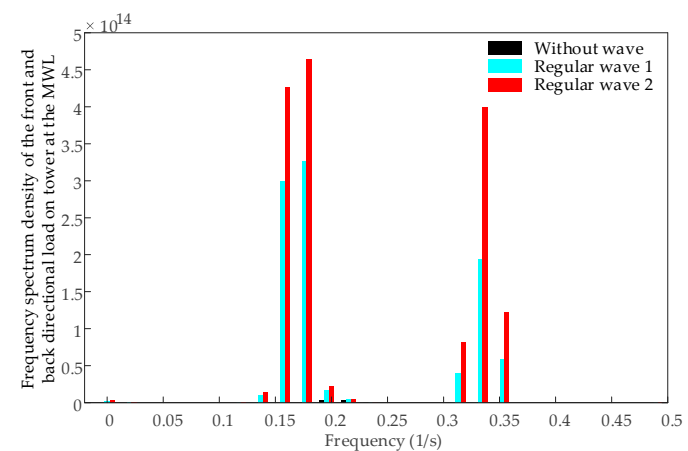

(b)

Figure 4. Time domain and frequency domain results of the fore-aft load on tower at the MWL without and with regular wave: (a) The fore-aft load on tower at the MWL; (b) Frequency spectrum density of the fore-aft load on tower at the MWL.

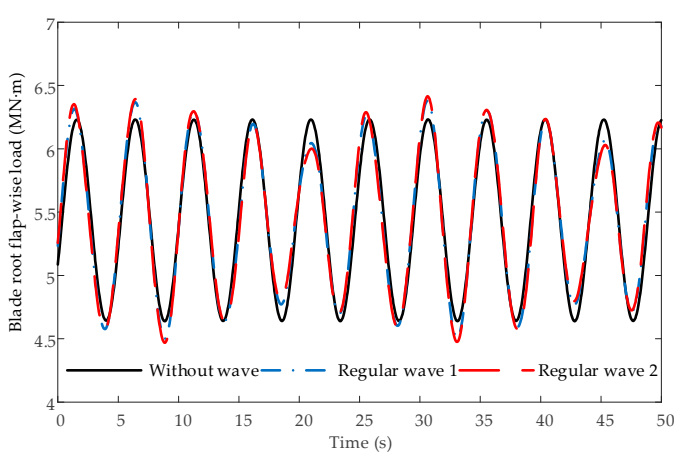

(a)

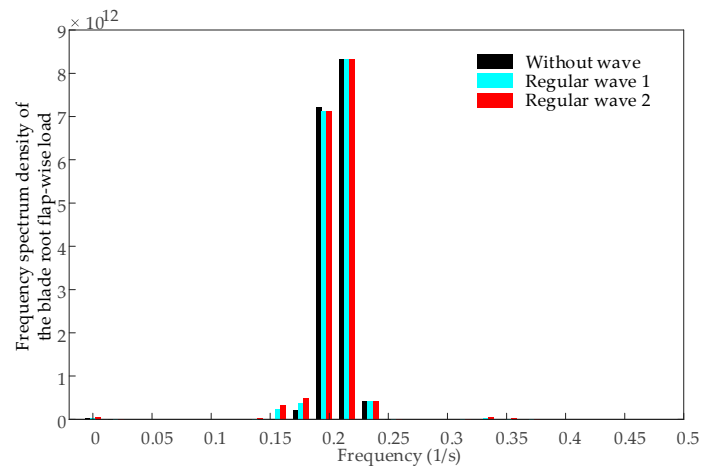

(b)

Figure 5. Time domain and frequency domain results of the blade root flap-wise load without and with regular wave: (a) The blade root flap-wise load; (b) Frequency spectrum density of the blade root flap-wise load. 


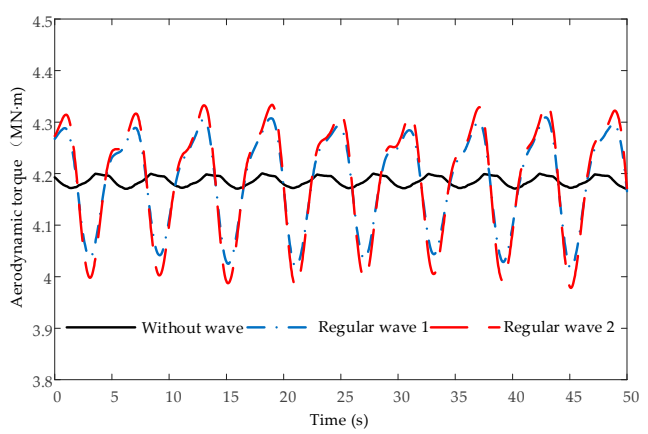

(a)

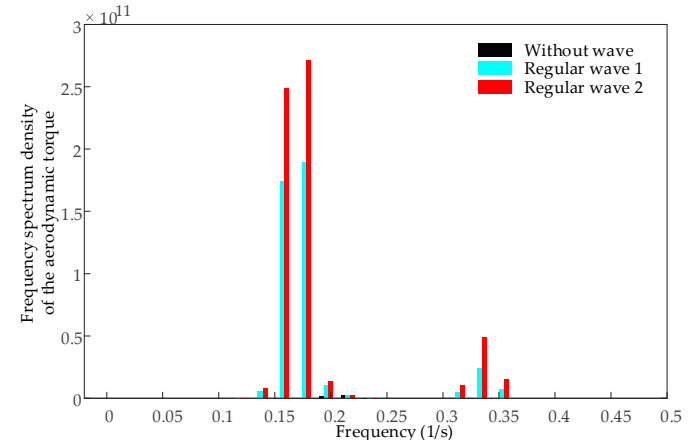

(b)

Figure 6. Time domain and frequency domain results of the aerodynamic torque without and with regular wave: (a) The aerodynamic torque; (b) Frequency spectrum density of the aerodynamic torque.

From Figure 4, the hydrodynamic frequency at $0.167 \mathrm{~Hz}$ directly impacts the tower and causes the low frequency oscillation at $0.167 \mathrm{~Hz}$ and $0.33 \mathrm{~Hz}$ (two times hydrodynamic frequency). According to statistics, the peak spectrum period of wave in China offshore is about 3-10 s, i.e., in the range of 0.1-0.33 Hz [39,40]. Therefore, it is very easy to cause low-frequency vibration of the tower in the direction of current. If the hydrodynamic frequency is similar to the vibration frequency of the tower, it will cause resonance.

From Figure 5, when the blade-tower interaction is considered, the vibration of the top of the tower caused by regular wave will increase the blade root flap-wise load fluctuations at the hydrodynamic frequency. However, the fluctuation of blade root flap-wise load at $1 \mathrm{P}$ frequency is slightly reduced under the influence of regular waves. In general, the effect of wave on blade root load is small due to the damp effect of tower and wind wheel. From Figure 6, when regular waves act on the wind turbine, a large fluctuating component of hydrodynamic frequency will be produced in the aerodynamic torque.

From Figures 4-6, it is found that the greater the wave height of the regular wave, the greater the impact of the wave on the vibration of the wind turbine and the tower, and the greater the fluctuation of the fore-aft load on tower at the MWL, blade root flap-wise load and aerodynamic torque.

\subsubsection{Simulation and Verification of the Effect of Random Waves on Wind Turbine}

The influence of random waves on the vibration characteristics of wind turbines is verified under constant wind conditions. In this case, the wind speed at the hub center is also constant at $14 \mathrm{~m} / \mathrm{s}$, and the wind and wave are in a consistent direction. In 'Random wave 1 ', the significant wave height of the random wave is $2.5 \mathrm{~m}$, and the spectrum peak period is $9.5 \mathrm{~s}$. In 'Random wave 2 ', the significant wave height of the random wave is $2.0 \mathrm{~m}$, and the spectrum peak period is $9.5 \mathrm{~s}$. The time-domain and frequency-domain comparison curves of load and torque are shown in Figures 7-9.

From Figures 7-9, it is found that the fore-aft load on the tower at the MWL and aerodynamic torque of the wind turbine are also significantly affected by random waves. Random waves can be regarded as the superposition of several cosine waves. The frequencies of the wave are mainly distributed in the range of $0-0.4 \mathrm{~Hz}$. The fore-aft load on the tower at the MWL and aerodynamic torque fluctuate greatly with the hydrodynamic frequency, which is caused by the random wave, and the greater the significant wave height of the random wave, the greater the fluctuation of the fore-aft load on the tower at the MWL and aerodynamic torque. However, due to the damp effect of the tower and wind wheel, the vibration caused by waves at the blade root is small. These conclusions are consistent with those in Section 5.1.1. 


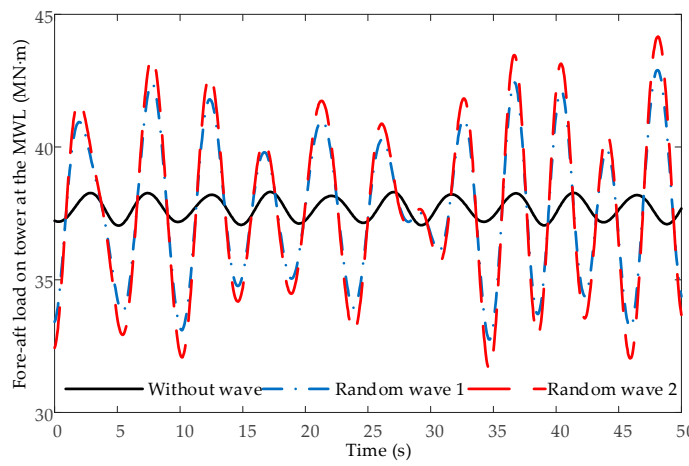

(a)

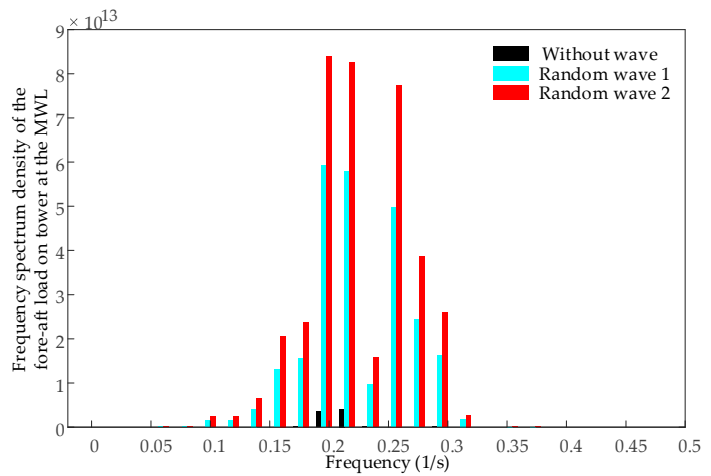

(b)

Figure 7. Time domain and frequency domain results of the fore-aft load on tower at the MWL without and with random wave: (a) The fore-aft load on tower at the MWL; (b) Frequency spectrum density of the fore-aft load on tower at the MWL.

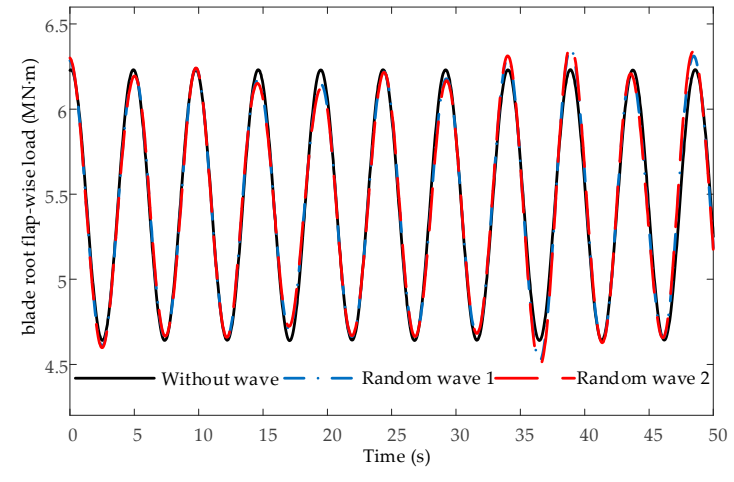

(a)

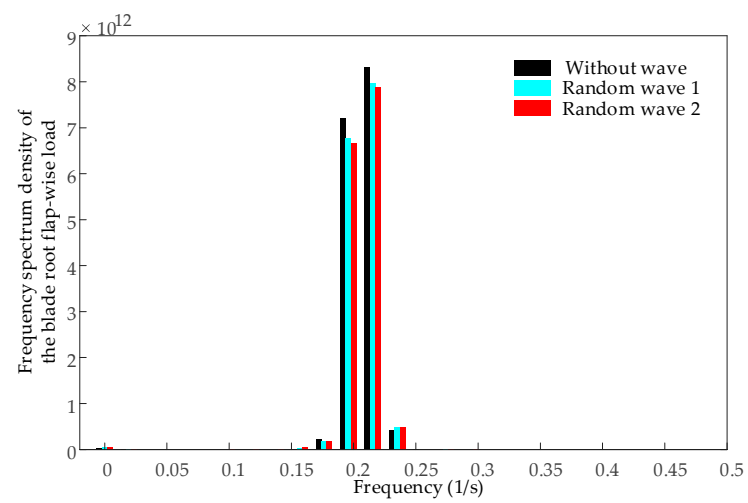

(b)

Figure 8. Time domain and frequency domain results of the blade root flap-wise load without and with random wave: (a) The blade root flap-wise load; (b) Frequency spectrum density of the blade root flap-wise load.

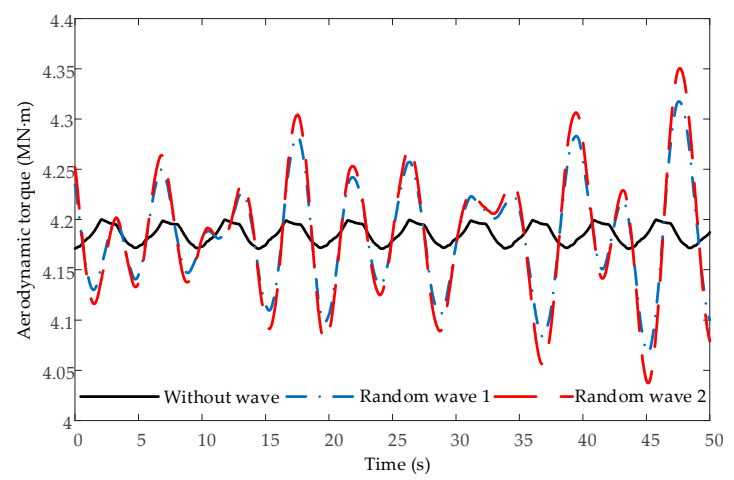

(a)

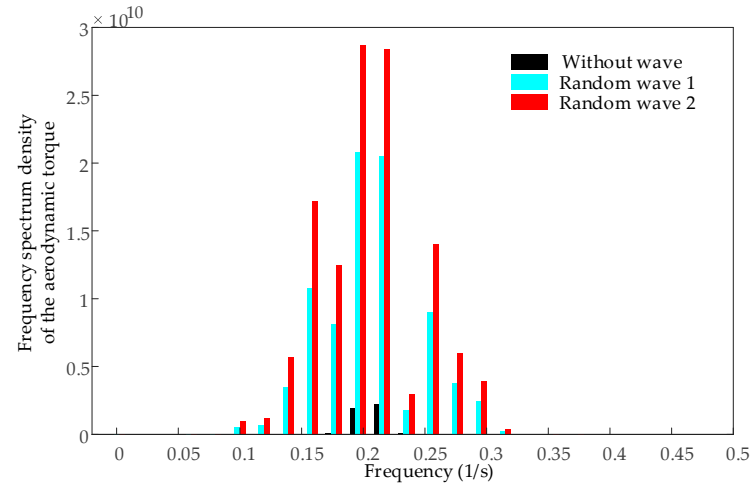

(b)

Figure 9. Time domain and frequency domain results of the aerodynamic torque without and with random wave: (a) The aerodynamic torque; (b) Frequency spectrum density of the aerodynamic torque.

\subsection{Determination of the Control Parameters}

In order to select the appropriate control parameters, the numerical statistical curves with different control parameters are drawn, as shown in Figure 10. In the simulation, the wind speed at the hub center is constant at $14 \mathrm{~m} / \mathrm{s}$, the regular wave height is $2.4 \mathrm{~m}$, the wave period is $6 \mathrm{~s}$, and the wind and 
wave are in a consistent direction. To select the appropriate control parameters, the standard deviations of aerodynamic torque, blade root flap-wise load and wind wheel speed are tracked since the standard deviation of dynamic responses is a better representation for the fluctuation level of vibration.

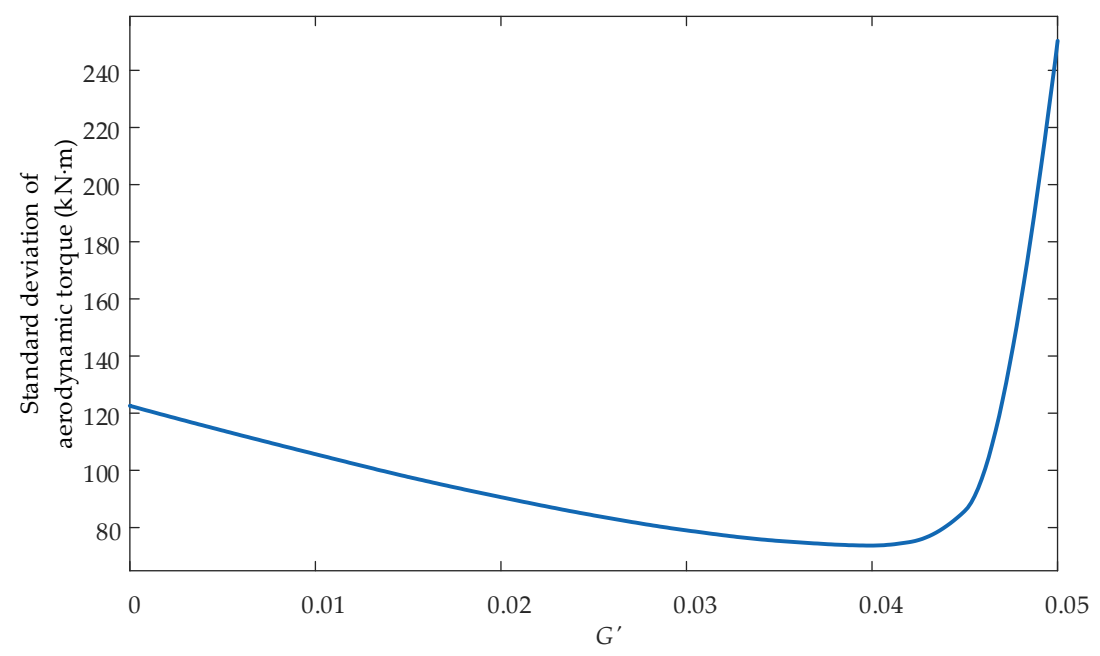

(a)

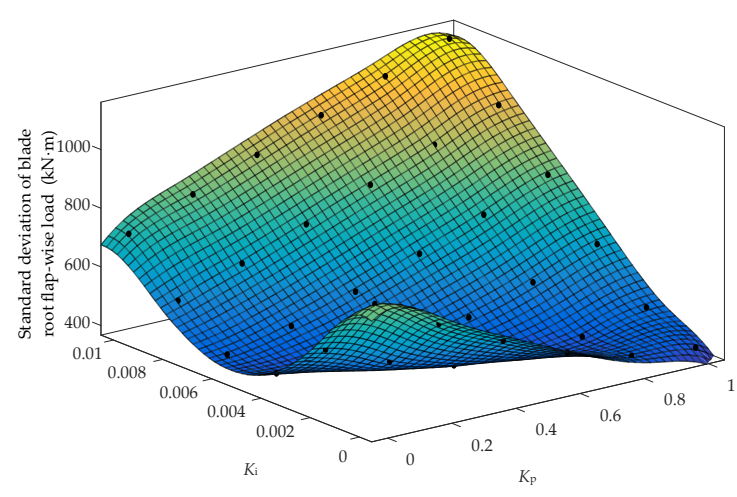

(b)

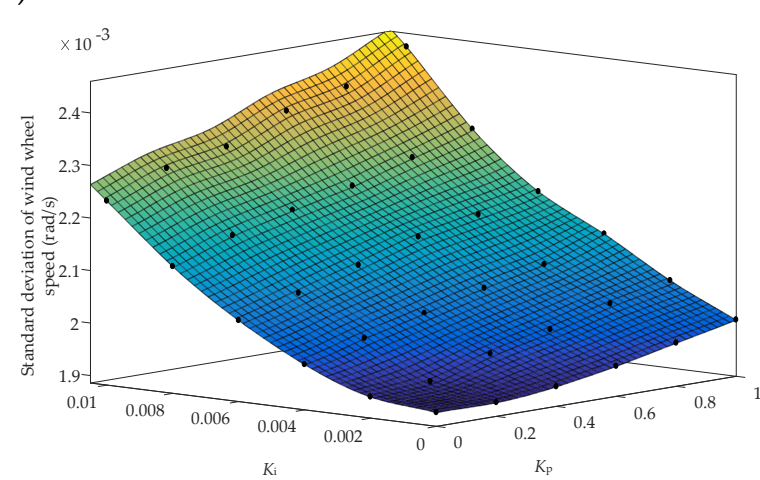

(c)

Figure 10. Control performance with different pitch control parameters: (a) Standard deviation of aerodynamic torque at different $G^{\prime}$; (b) Standard deviation of blade root flap-wise load at different $K_{p}$, $K_{i}$; (c) Standard deviation of wind wheel speed at different $K_{p}, K_{i}$.

Figure 10a shows that the standard deviation of aerodynamic torque decreases first and then increases with the increase of $G^{\prime}$. According to Equation (18), when $-\left(\hat{T}_{a e r o}\right)_{\beta}^{\prime} G^{\prime}>\left(\hat{T}_{a e r o}\right)_{V}^{\prime}$, the additional torque will add a new fluctuation component after offsetting the fluctuating component of hydrodynamic frequency in aerodynamic torque. So, when $G^{\prime}>0.04$, the standard deviation of aerodynamic torque increases with the increase of $G^{\prime}$.

From Figure 10b,c, it can be seen that the standard deviation of wind wheel speed increases with the increase of $K_{p}$ and $K_{i}$, and within a certain range, the standard deviation of the blade root flap-wise load decreases with the increase of $K_{p}$ and $K_{i}$, but when $K_{p}$ and $K_{i}$ are large at the same time, the vibration of the blade root will be aggravated. Considering the stability of the wind wheel speed, that is, the stability of output active power, and further considering the stability of the blade root flap-wise load, the $K_{p}$ value in this paper should be less than 0.6 , and the $K_{i}$ value should be less than 0.004 .

For comparison, here we use turbulent wind and random waves instead of constant wind speed and regular waves. Suppose the turbulent wind intensity is 0.08 , the average wind speed at the hub is $14 \mathrm{~m} / \mathrm{s}$, the significant wave height of the random wave is $2.5 \mathrm{~m}$, the spectrum peak period is $9.5 \mathrm{~s}$, and the wind and waves are in a consistent direction. The response of aerodynamic torque, blade root 
load and wind wheel speed of the wind turbine with different pitch control parameters after changing working conditions is shown in Figure 11.

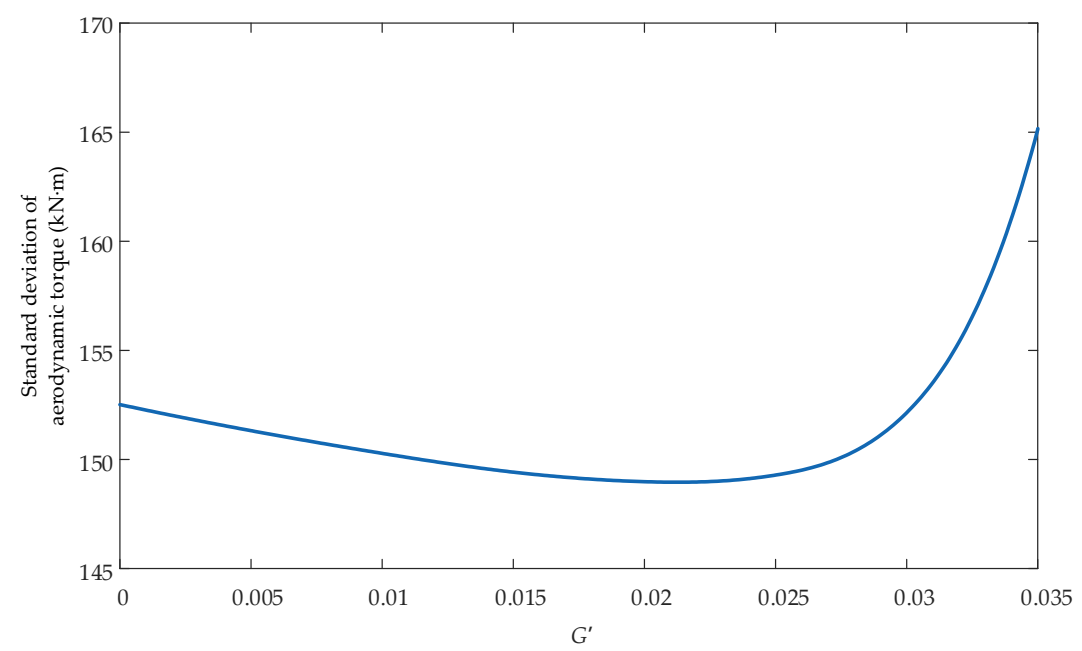

(a)

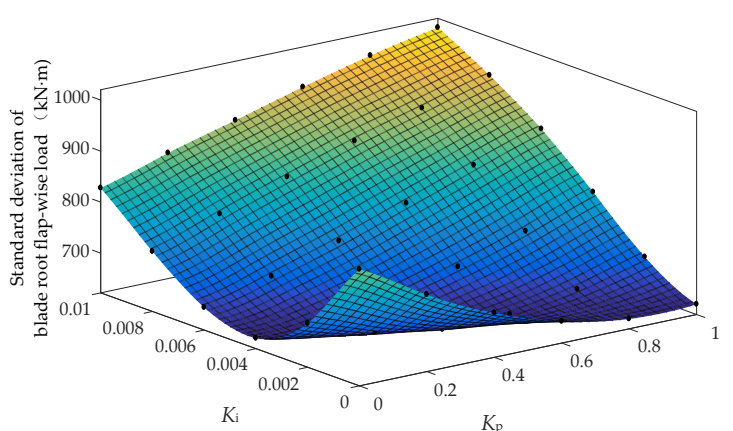

(b)

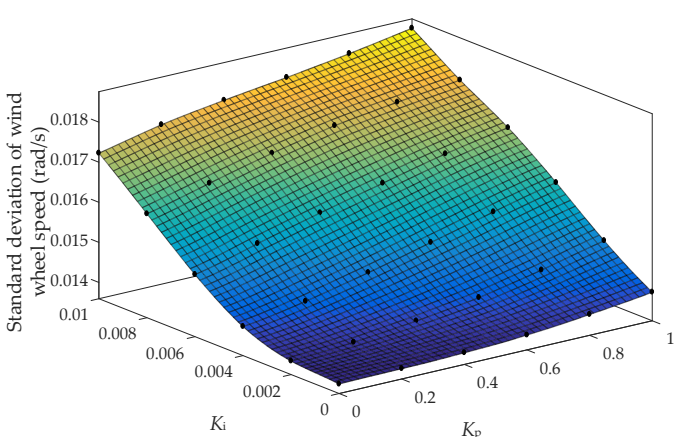

(c)

Figure 11. Control performance with different pitch control parameters under random wind-wave conditions: (a) Standard deviation of aerodynamic torque at different $G^{\prime}$; (b) Standard deviation of blade root flap-wise load at different $K_{p}, K_{i}$; (c) Standard deviation of wind wheel speed at different $K_{p}, K_{i}$.

From Figure 11, it can be seen that the response of aerodynamic torque, blade root load and wind wheel speed of the wind turbine with different pitch control parameters under random wind-wave conditions is similar to that under regular wind-wave conditions. The suitable ranges of $K_{p}$ and $K_{i}$ remain unchanged, but the suitable range of $G^{\prime}$ is reduced.

Considering that the control strategy can achieve the effect of vibration reduction without causing too much negative impact on the system, and considering the coupling relationship between the vibration of the wind turbine, the parameters of the controller are selected as follows: $G^{\prime}=0.022$, $K_{p}=0.1, K_{i}=0.002$.

\subsection{Simulation and Verification of the Pitch Angle Control Strategy}

For comparison, simulations with the collective pitch control (CPC), the individual pitch control strategy based on combined azimuth and load feedback (CALF-IPC) [7] and the improved individual pitch control strategy (IIPC) proposed in this paper, are implemented both in the time domain and frequency spectrum respectively. In this case, the constant wind and regular wave conditions are the same as that in Section 5.2, wind shear and tower shadow are considered. The simulation results are shown in Figures 12-14. 


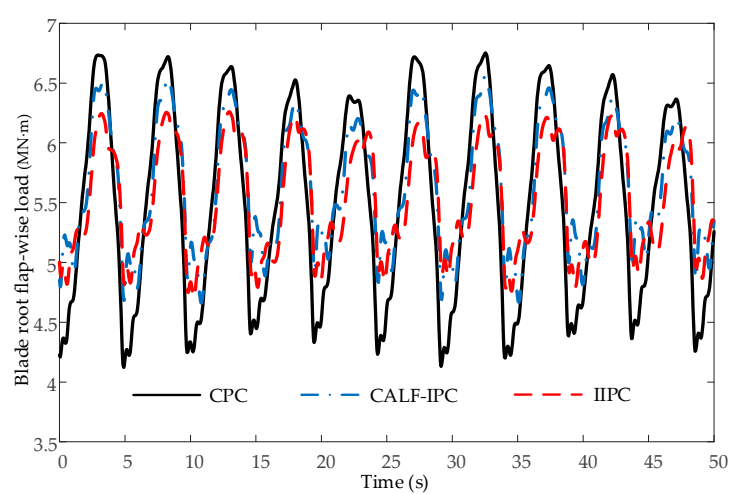

(a)

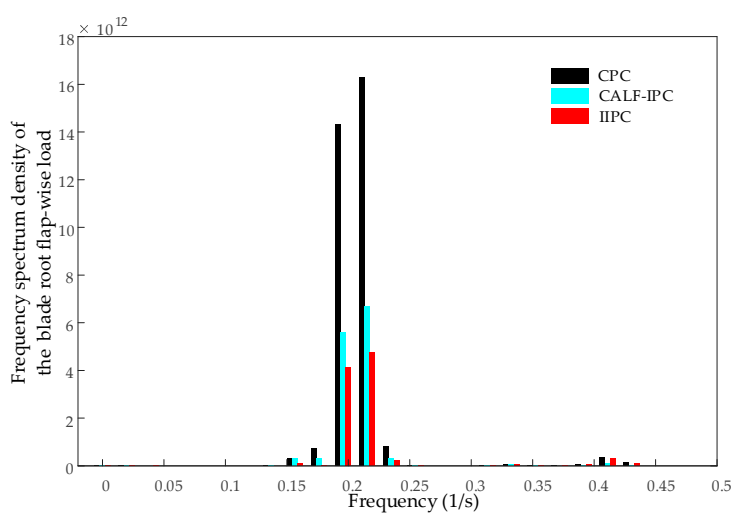

(b)

Figure 12. Time domain and frequency domain results of blade root flap-wise load under different control: (a) Curves of the blade root flap-wise load; (b) Frequency spectrum density of the blade root flap-wise load.

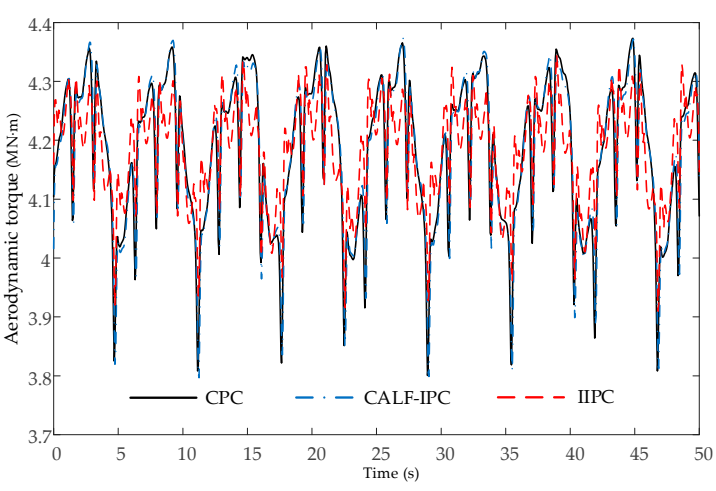

(a)

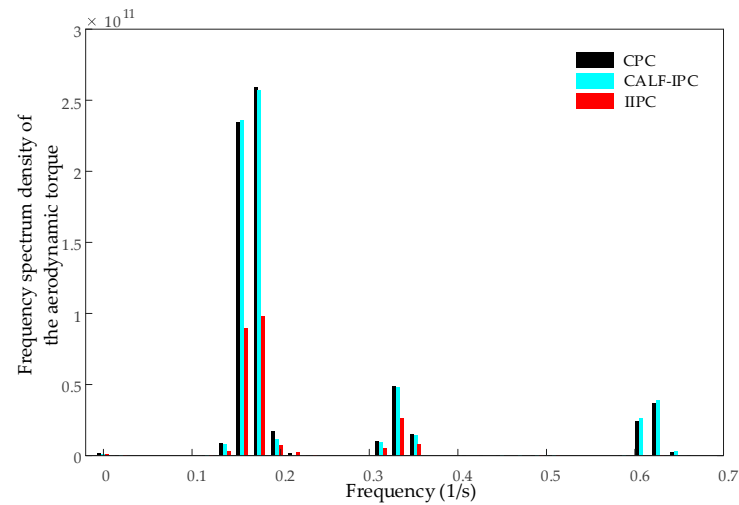

(b)

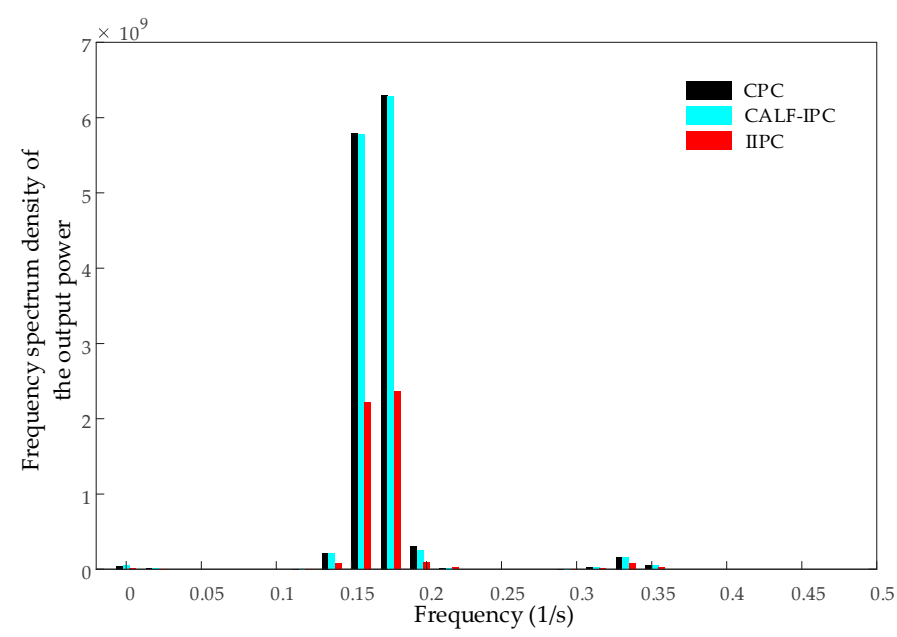

(c)

Figure 13. Time domain and frequency domain results of aerodynamic torque and output power under different control: (a) Curves of the aerodynamic torque; (b) Frequency spectrum density of the aerodynamic torque; (c) Frequency spectrum density of the output power. 


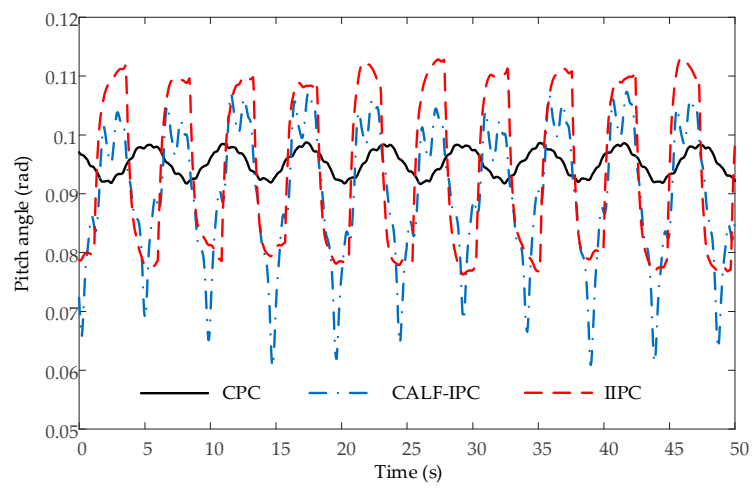

(a)

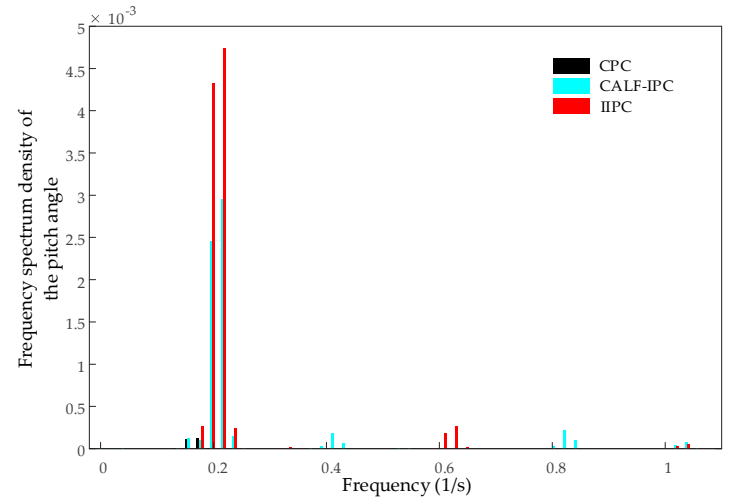

(b)

Figure 14. Time domain and frequency domain results of pitch angle under different control: (a) Curves of the pitch angle; (b) Frequency spectrum density of the pitch angle.

From Figure 12, it can be observed that both the proposed IIPC and the CALF-IPC contribute to reducing the fluctuation amplitude of blade root flap-wise load by periodically adjusting the pitch angle of three blades. Moreover, the proposed IIPC can better reduce the fluctuation of the blade root flap-wise load. It can be seen from Figure $12 \mathrm{~b}$ that the $1 \mathrm{P}$ fluctuation component in blade root flap-wise load under the proposed IIPC is reduced by about $77 \%$ and $33 \%$, respectively, compared with that under the CPC and the CALF-IPC.

Meanwhile, shown in Figure 13, the proposed IIPC has better effectiveness to suppresses the fluctuation of aerodynamic torque than CALF-IPC. As can be seen from Figure 13b, the frequency spectral density of the aerodynamic torque at the hydrodynamic frequency $(0.167 \mathrm{~Hz})$ and at the $3 \mathrm{P}$ is noticeably reduced. The results show that the hydrodynamic frequency fluctuation component and the $3 \mathrm{P}$ fluctuation component in the aerodynamic torque are effectively suppressed. Furthermore, decreased fluctuation components in the output power with a frequency of $0.167 \mathrm{~Hz}$ are also observed in Figure 13c. This is because of the direct correlation between aerodynamic torque and output power. Therefore, the proposed IIPC reduces the fluctuation of aerodynamic load and improves the stability of output power.

However, from Figure 14, under the proposed IIPC, the fluctuation of the pitch angle is increased, especially at the hydrodynamic frequency, $1 \mathrm{P}$ and $3 \mathrm{P}$ frequency, with the fluctuation of the blade root flap-wise load and aerodynamic torque reduced. This might be disadvantageous for pitch actuators, as it can slightly exacerbate fatigue damage to pitch actuators.

In summary, simulation results demonstrate the effectiveness of the proposed IIPC in the smoothing fluctuation of the wind turbine blade root flap-wise load and aerodynamic torque caused by wave impact, wind shear and tower shadow, which is accomplished by aggravating the fatigue damage of the pitch mechanism via frequent pitch angle adjustment. In general, the proposed IIPC can suppress the vibration of the wind turbine, and it has a certain economy.

In addition, considering wind shear and tower shadow, the effectiveness of the control strategy under turbulent wind and random wave conditions is studied, and the turbulent wind and random wave conditions are the same as that in Section 5.2. The simulation results are shown in Figure 15.

The simulation results show that by modifying the pitch angle, the proposed IIPC can restrain the $1 \mathrm{P}$ pulsation of blade root flap-wise load and weaken the hydrodynamic frequency pulsation $(0 \sim 0.4 \mathrm{~Hz})$ and 3P pulsation of aerodynamic torque and output power, which verifies the effectiveness of the proposed IIPC under turbulent wind and random wave conditions. 


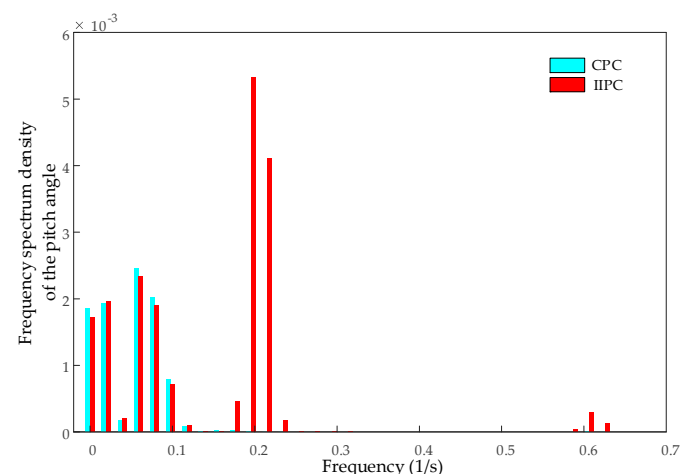

(a)

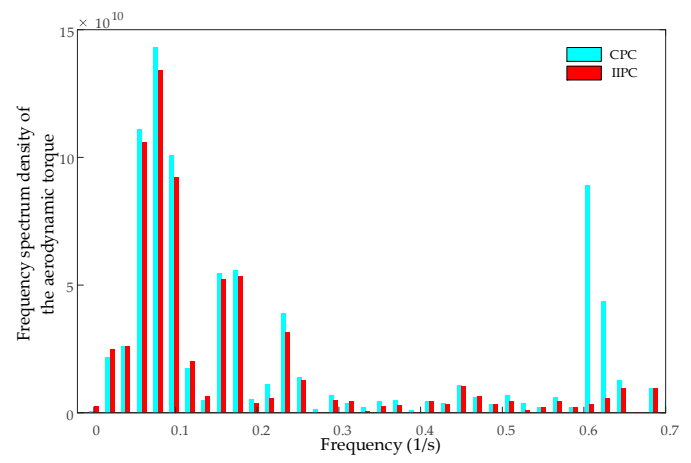

(c)

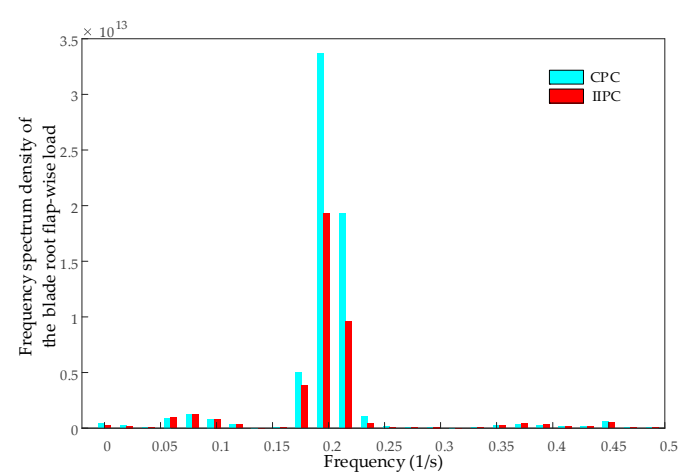

(b)

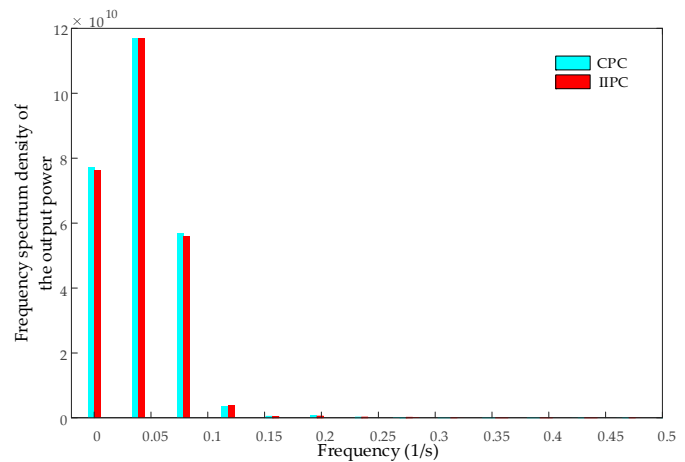

(d)

Figure 15. Simulation results of different data of wind turbine under turbulent wind and random wave: (a) Frequency spectrum density of the pitch angle; (b) Frequency spectrum density of the blade root flap-wise load; (c) Frequency spectrum density of the aerodynamic torque; (d) Frequency spectrum density of the output power.

\section{Conclusions}

As the size of offshore wind turbines continues rising, the low-frequency vibration related to hydrodynamic frequency caused by waves is becoming nonnegligible. The load and torque pulsation of wind turbines caused by wind shear and tower shadow becomes more serious, which greatly increases the fatigue damage of wind turbines and shortens the service life of wind turbines. For this reason, in this paper, the mechanism of how wind and waves jointly affect the vibration characteristics of offshore wind turbines is analyzed, and an improved individual pitch control strategy is proposed to suppress fluctuations caused by wind and waves. The related main conclusions are summarized as follows:

1. A mathematical model of how waves affect load and aerodynamic torque of wind turbines is derived, and we show the existence of fluctuating components of the hydrodynamic frequency in both blade root load and the aerodynamic torque. Simulation results further support the theoretical analysis. It is found that the greater the wave height of the wave, the greater the impact of the wave on the vibration of the wind turbine and the tower, and the greater the fluctuation of the fore-aft load on the tower at the MWL and aerodynamic torque.

2. The parameters of the proposed controller can be determined by simulations considering the trade-off between the vibration reduction and the impact on the system of the control strategy, as well as the coupling relationship between the vibration of the wind turbines.

3. By fine-tuning the pitch angle, the individual pitch control strategy proposed in this paper can not only effectively alleviate the wind turbine load fluctuation caused by wind and waves, but also restrain the wind turbine torque pulsation, thus further smoothing its output power, which is more economical than the individual pitch control method based on combined azimuth and load feedback. 
In addition to waves, the complexity of the operation environment of offshore wind turbines is further enhanced by ocean currents, tides and other factors. Vibration control strategies of offshore wind turbines under the influence of multiple environmental factors will be studied in the future.

Author Contributions: Conceptualization, H.L. and M.Z.; methodology, H.L., S.Y. and M.Z.; software, S.Y., W.T. and M.Z.; validation, S.Y., W.T. and M.Z.; formal analysis, H.L., M.Z. and X.Y.; investigation, S.Y. and W.T.; writing - original draft preparation, H.L., S.Y. and W.T.; writing-review and editing, H.L., M.Z. and B.X. All authors have read and agreed to the published version of the manuscript.

Funding: This research was funded by the "111" project of "Renewable Energy and Smart Grid" of China, grant number B14022; the Fundamental Research Funds for the Central Universities of China, grant number 2016B07014; the National Natural Science Foundation of China, grant number 51607058; and Six Talent Peaks Project of Jiangsu Province of China, grant number 2015-XNY-005.

Conflicts of Interest: The authors declare no conflict of interest. The funders had no role in the design of the study; in the collection, analyses, or interpretation of data; in the writing of the manuscript, or in the decision to publish the results.

\section{References}

1. Snyder, B.; Kaiser, M.J. Ecological and economic cost-benefit analysis of offshore wind energy. Renew. Energy 2009, 34, 1567-1578. [CrossRef]

2. Bossanvi, E.A. Individual blade pitch control for load reduction. Wind Energy 2003, 6, 119-128. [CrossRef]

3. Dolan, D.S.L.; Lehn, P.W. Simulation model of wind turbine $3 p$ torque oscillations due to wind shear and tower shadow. IEEE Trans. Energy Convers. 2006, 21, 717-724. [CrossRef]

4. Qiao, Y.; Han, S.; Deng, Y.; Liu, Y.; Dong, J.; Pan, L.; Li, R.; Zhao, B. Research on variable pitch control strategy of wind turbine for tower vibration reduction. J. Eng. 2017, 2017, 2005-2008. [CrossRef]

5. Lio, W.H.; Jones, B.L.; Rossiter, J.A. Estimation and control of wind turbine tower vibrations based on individual blade-pitch strategies. IEEE Trans. Control. Syst. Technol. 2019, 27, 1820-1828. [CrossRef]

6. Kanev, S.; Van, E.T. Exploring the limits in individual pitch control. In Proceedings of the European Wind Energy Conference and Exhibition, Marseille, France, 16-19 March 2009; pp. 679-704.

7. Liu, H.M.; Tang, Q.Q.; Chi, Y.N.; Zhang, Z.K.; Yuan, X.L. Vibration reduction strategy for wind turbine based on individual pitch control and torque damping control. Int. Trans. Electr. Energy Syst. 2016, 26, 2230-2243. [CrossRef]

8. Coral-Enriquez, H.; Cortes-Romero, J.; Dorado-Rojas, S.A. Rejection of varying-frequency periodic load disturbances in wind-turbines through active disturbance rejection-based control. Renew. Energy 2019, 141, 217-235. [CrossRef]

9. Jones, B.L.; Lio, W.H.; Rossiter, J.A. Overcoming fundamental limitations of wind turbine individual blade pitch control with inflow sensors. Wind Energy 2018, 21, 922-936. [CrossRef]

10. Ossmann, D.; Theis, J.; Seiler, P. Load reduction on a clipper liberty wind turbine with linear parameter-varying individual blade pitch control. Wind Energy 2017, 20, 1771-1786. [CrossRef]

11. Fitzgerald, B.; Staino, A.; Basu, B. Wavelet-based individual blade pitch control for vibration control of wind turbine blades. Struct. Control. Health Monit. 2019, 26, 1-12. [CrossRef]

12. Civelek, Z.; Luy, M.; Cam, E.; Mamur, H. A new fuzzy logic proportional controller approach applied to individual pitch angle for wind turbine load mitigation. Renew. Energy 2017, 111, 708-717. [CrossRef]

13. He, K.; Qi, L.; Zheng, L.; Chen, Y. Combined pitch and trailing edge flap control for load mitigation of wind turbines. Energies 2018, 11, 2519. [CrossRef]

14. Mohammadi, E.; Fadaeinedjad, R.; Moschopoulos, G. Implementation of internal model based control and individual pitch control to reduce fatigue loads and tower vibrations in wind turbines. J. Sound Vibr. 2018, 421, 132-152. [CrossRef]

15. Zhang, Y.Q.; Hu, W.H.; Chen, Z.; Cheng, M. Individual pitch control for mitigation of power fluctuation of variable speed wind turbines. In Proceedings of the 10th International Power and Energy Conference (IPEC), Ho Chi Minh City, Vietnam, 12-13 December 2012; pp. 638-643.

16. Dou, Z.L.; Ling, Z.B.; Cai, X. Torque smoothing control of wind turbine generator system using individual pitch control. In Proceedings of the 2012 IEEE 7th International Power Electronics and Motion Control Conference-ECCE Asia (IPEMC 2012), Harbin, China, 2-5 June 2012; pp. 2157-2161. 
17. Imran, R.M.; Hussain, D.M.A.; Chowdhry, B.S. Parameterized disturbance observer based controller to reduce cyclic loads of wind turbine. Energies 2018, 11, 1296. [CrossRef]

18. Tian, W.; Pan, W.X.; Shao, Y.X.; Xu, B.F.; Liu, H.M.; Hou, Y.H. Individual pitch control strategy for reducing aerodynamic loads and torque ripples. IEEJ Trans. Electr. Electron. Eng. 2019, 14, 1624-1632. [CrossRef]

19. Agarwal, P.; Manuel, L. Extreme loads for an offshore wind turbine using statistical extrapolation from limited field data. Wind Energy 2008, 11, 673-684. [CrossRef]

20. Kim, D.H.; Lee, S.G. Reliability analysis of offshore wind turbine support structures under extreme ocean environmental loads. Renew. Energy 2015, 79, 161-166. [CrossRef]

21. Passon, P.; Branner, K. Load calculation methods for offshore wind turbine foundations. Ships Offshore Struct. 2014, 9, 433-449. [CrossRef]

22. Ziegler, L.; Voormeeren, S.; Schafhirt, S.; Muskulus, M. Sensitivity of wave fatigue loads on offshore wind turbines under varying site conditions. In Proceedings of the 12th Deep Sea Offshore Wind R and D Conference (EERA DeepWind 2015), Trondheim, Norway, 4-6 February 2015; pp. 193-200.

23. Hemmati, A.; Oterkus, E.; Barltrop, N. Fragility reduction of offshore wind turbines using tuned liquid column dampers. Soil Dyn. Earthq. Eng. 2019, 125, 1-16. [CrossRef]

24. Namik, H.; Stol, K. Performance analysis of individual blade pitch control of offshore wind turbines on two floating platforms. Mechatronics 2011, 21, 691-703. [CrossRef]

25. Namik, H.; Stol, K. Individual blade pitch control of floating offshore wind turbines. Wind Energy 2010, 13, 74-85. [CrossRef]

26. Sarkar, S.; Chen, L.; Fitzgerald, B.; Basu, B. Multi-resolution wavelet pitch controller for spar-type floating offshore wind turbines including wave-current interactions. J. Sound Vibr. 2020, 470, 1-23. [CrossRef]

27. Chakrabarti, S.K.; Kriebel, D. Wave kinematics for simulated shallow water storm waves-Analysis and experiments. Ocean. Eng. 1997, 24, 835-865. [CrossRef]

28. Zaheer, M.M.; Islam, N. Dynamic response of articulated towers under correlated wind and waves. Ocean. Eng. 2017, 132, 114-125. [CrossRef]

29. Zheng, G.; Huang, X.; Xu, D. A discrete correction scheme for envelope approach of wave group statistics. Coast. Eng. 2004, 50, 225-230.

30. Wang, H.; Zhu, J.; Yang, J.; Shi, C. A semiempirical algorithm for SAR wave height retrieval and its validation using Envisat ASAR wave mode data. Acta Oceanol. Sin. 2012, 31, 59-66. [CrossRef]

31. Raed, K.; Guedes Soares, C. Variability effect of the drag and inertia coefficients on the Morison wave force acting on a fixed vertical cylinder in irregular waves. Ocean Eng. 2018, 159, 66-75. [CrossRef]

32. Henry, R.B.; George, H.S. Structural Dynamics: Concepts and Applications; CRC Press: Boca Raton, FL, USA, 2017; pp. 44-45.

33. Nigam, N.C.; Jennings, P.C. Earthquake Engineering Research Laboratory Report. In Digital Calculation of Response Spectra from Strong Motion Earthquake Records; California Institute of Technology: Pasadena, CA, USA, 1968.

34. Murtagh, P.J.; Bash, B.; Broderick, B.M. Along-wind response of a wind turbine tower with blade coupling subjected to rotationally sampled wind loading. Eng. Struct. 2005, 27, 1209-1219. [CrossRef]

35. Shen, X.; Zhu, X.C.; Du, Z.H. Wind turbine aerodynamics and loads control in wind shear flow. Energy 2011, 36, 1424-1434. [CrossRef]

36. Chen, L.; Basu, B. Wave-current interaction effects on structural responses of floating offshore wind turbines. Wind Energy 2019, 22, 327-339. [CrossRef]

37. Zhang, Y.; Chen, Z.; Hu, W.; Cheng, M. Flicker mitigation by individual pitch control of variable speed wind turbines with DFIG. IEEE Trans. Energy Convers. 2014, 29, 20-28. [CrossRef]

38. Fu, L.; Wei, Y.D.; Fang, S.; Tian, G.; Zhou, X.J. A wind energy generation replication method with wind shear and tower shadow effects. Adv. Mech. Eng. 2018, 10,1-11. [CrossRef]

39. Chen, Z.; Chen, X.; Zhao, C.; Wang, Z. Wave height and wave period derived from a shipboard coherent s-band wave radar in the South China Sea. Remote Sens. 2019, 11, 2812. [CrossRef]

40. Chen, F.; Duan, D.; Han, Q.; Yang, X.; Zhao, F. Study on force and wave energy conversion efficiency of buoys in low wave energy density seas. Energy Convers. Manag. 2019, 182, 191-200. [CrossRef]

(C) 2020 by the authors. Licensee MDPI, Basel, Switzerland. This article is an open access article distributed under the terms and conditions of the Creative Commons Attribution (CC BY) license (http://creativecommons.org/licenses/by/4.0/). 